\title{
Thermo-oxidative and weathering degradation affecting coloration performance of lac dye
}

\author{
Prapaipim Nacowong and Sunan Saikrasun ${ }^{*}$
}

*Correspondence:
sunan.s@msu.ac.th
Creative Chemistry
Research Unit,
Department of Chemistry
and Center of Excellence
for Innovation in Chemistry,
Faculty of Science,
Mahasarakham University,
Mahasarakham 44150,
Thailand

*Correspondence:

Department of Chemistry

and Center of Excellence

for Innovation in Chemistry,

Mahasarakham University,

Thailand

\begin{abstract}
Thermo-oxidative stability of lac dye was studied by simultaneous thermogravimetry (TG) and differential scanning calorimetry under nonisothermal and isothermal modes in air. The thermal stability change of lac dye was characterized by FTIR and UV-Vis spectroscopy. The TG profiles of lac dye showed at least three steps of mass loss. The first mass loss (about $8 \%$ ) found in the range of $40-150^{\circ} \mathrm{C}$ mainly corresponded to the evaporation of moisture whereas the next two major steps were found with mass losses of $50\left(150-440^{\circ} \mathrm{C}\right)$ and $25 \%\left(440-550^{\circ} \mathrm{C}\right)$. The FTIR results indicate that the degradation of the major mass loss step $\left(150-440^{\circ} \mathrm{C}\right)$ mainly involved the thermooxidative reaction at carboxylic groups in conjugation with the $\mathrm{C}=\mathrm{C}$ bonds of the anthraquinone ring. The absorbance profiles of lac dye solutions showed that the remarkable drop of absorbability was observed when the dye was heated to elevated temperatures $\left(>150^{\circ} \mathrm{C}\right)$. The results obtained from isothermal investigation also indicated the thermo-oxidative stability dependence of heating temperature. The apparent activation energy of lac dye calculated using isoconversional methods was higher under dynamic than under isothermal heating. Long period of weathering exposure mainly affected the $\mathrm{O}-\mathrm{H}$ bonds of hydroxyl and carboxylic groups, and hence lowering the absorbability of lac dye. These results provided helpful information that can give support in the maintenance, preparation, dyeing and application stages of lac dye.
\end{abstract}

Keywords: Lac, Thermogravimetry, Degradation, Absorbance, Kinetics

\section{Introduction}

The natural dyes have been widely used, especially for textile dyeing, coloring food, painting and in printing. However, with the rapid incursion of synthetic dyes, natural dyes undergo a setback. During the past few decades, the problems concerning the environmentally harmful effects and serious health hazards have been raised regarding the use of synthetic dyes. Therefore, the use of natural dyes is considerable current interest as these dyes are eco-friendly, safe for body contact, unsophisticated, harmonized and renewable (Nayar et al. 1994; Downham and Collins 2000).

For the dye molecules, the chemical structure is normally divided as the chromophore (main skeleton) and auxochrome (substituent groups) parts. The chromophore part generally determines the light fastness properties. Oppositely, the change in fastness properties is dominated by the auxochromes (Cristea and Vilarem 2006). Flavonoid 
compounds are mostly found as the main components in natural dyes and the remaining components anthraquinones, naphtoquinones and indigoids. Anthraquinones and indigoids typically exhibit superior light fastness. Although the numerous advantages have been gained from the natural dyes, the color fading due to the degradation of dye is still be one of the major problems in textile color. Normally, the color fading directly affects in the loss of intact dye molecule resulting in the change of original dye color (Ahn et al. 2014). In general, the stability of natural dye is mostly influenced by the chemical and physical states of the dye. Moreover, the source and the intensity of illumination, humidity, temperature (heat), and the atmospheric pollution as the external factors can affect the stability of natural dyes as well. The light source containing UV radiation is one of the important factors that affect the stability of the dyes by photofading process (McLaren 1956; Padfield and Landi 1996; Gantz and Sumner 1957). Under exposing to light, both temperature and humidity can influence the fading rate of dyed textiles (Egerton and Morgan 1970). In addition, the natural dyes can react with gas contaminants in the atmosphere, e.g., sulfur dioxide and oxides of nitrogen and ozone even in the absence of light. In terms of thermal affecting stability, it is known that higher temperature accelerates the oxidation of the natural dyes. It has been reported that the oxidation reaction of amor cork tree dye is accelerated two times by every $2{ }^{\circ} \mathrm{C}$ increase in temperature under heating in $100{ }^{\circ} \mathrm{C}$ oven (Ramos et al. 1995; Ahn 2011). Thermal degradation behavior of the alizarin and Phellodendron bark, alizarin and indirubin has also been studied by GC-MS and HPLC-DAD-MS (Ahn 2011; Ahn and Obendorf 2004). In addition, Ahn et al. (2014) investigated the thermal resistance of the natural dyes. The thermal stabilizing performance of alizarin and purpurin was attributed to the formation of fiber-metaldye chelated complex by aluminum or iron ions mordanting prior to dyeing.

Stick lac, a secretion of the insect Coccus laccae (Laccifer lacca Kerr), is a natural material used for preparation of lac dye (Moeyes 1993). The lac dye extracted from the stick lac has high potential in many fields of applications. For example, it is used as a cosmetics ingredient, for coloring food, oil painting and dyeing textiles (Moeyes 1993; Chairat et al. 2005; Janhom et al. 2004; Kongkachuichay et al. 2002; Kamel et al. 2007; Boonla and Saikrasun 2013; Sribenja and Saikrasun 2015). The main components in the soluble part of the stick lac are consisted of anthraquinone-based components. These are laccaic acids A (40 \%), B (15\%) and C (10 \%) (w/v) (Oka et al. 1998). The chemical structures of laccaic acids A-C are shown in Fig. 1. However, although lac dye is extensively used as natural colorants for many application routes, to the best of our knowledge, the systematic studies on thermo-oxidative and weathering degradations of lac dye have not been reported. In the present study, the effects of dynamic and isothermal heating and weathering on stability of lac dye were investigated. The FTIR and UV-Vis spectroscopy were used to monitor chemical changes in relation to the absorbability of lac dye. The obtained results are useful for prolonging the material lifetime under stability awareness during every stages material utilizations, especially in textile dyeing applications. 
<smiles>CNCCc1ccc(O)c(-c2c(O)c(O)c3c(c2O)C(=O)c2cc(O)c(C(=O)O)c([O+]=O)c2C3=O)c1</smiles>

a Laccaic acid $\mathrm{A}(\mathrm{MW}=537)$<smiles>O=C(O)c1c(O)cc2c(c1C(=O)O)C(=O)c1c(O)c(-c3cc(CCO)ccc3O)c(O)c(O)c1C2=O</smiles>

b Laccaic acid $\mathrm{B}(\mathrm{MW}=496)$<smiles>NC(Cc1ccc(O)c(-c2c(O)c(O)c3c(c2O)C(=O)c2cc(O)c(C(=O)O)c(C(=O)O)c2C3=O)c1)C(=O)O</smiles>

C Laccaic acid C $(\mathrm{MW}=539)$

Fig. 1 Chemical structures of the major anthraquinone-based components in lac dye; a laccaic acid A, b laccaic acid $B$ and $\mathbf{c}$ laccaic acid $C$

\section{Methods}

\section{Materials}

Crude stick lac was provided by the local villagers living in the Khon Kean province, Thailand. The lac dye was prepared in the form fine powder. The preparation procedure was described in our previous article (Sribenja and Saikrasun 2015).

\section{Nonisothermal and isothermal gravimetric analysis}

TA instruments, SDT Q600 (Luken's drive, New Castle, DE) was employed for thermal degradation investigation. The lac dye sample of about $10 \mathrm{mg}$ was loaded in alumina crucible and then dynamically heated from ambient temperature to the selected temperatures as $60,70,80,90,110,130,150,250,350$ and $600{ }^{\circ} \mathrm{C}$ using a heating rate of $10{ }^{\circ} \mathrm{C} /$ $\mathrm{min}$. The total times used for dynamic heating to the selected temperatures were 3,4 , $5,6,8,10,12,22,32$ and $57 \mathrm{~min}$., respectively. The experiment was carried out in air atmosphere with the gas flow rate of $100 \mathrm{~mL} / \mathrm{min}$. The analysis of TG and DSC data was similarly done as described in our previous communication (Saengsuwan and Saikrasun 2012). In case of isothermal test, the isothermal degradation was investigated at $90,110,130$, and $150^{\circ} \mathrm{C}$ for $100 \mathrm{~min}$. The procedure of isothermal heating analysis was also described in our previous article (Saengsuwan and Saikrasun 2012). In this work, the TG analysis data were gained from three measurements. The activation energy of thermo-oxidative decomposition for the lac dye was examined using isoconversional kinetic analysis. 


\section{FTIR characterization}

The structural change of lac dye was characterized by FT-IR spectroscopy (Spectrum GX-1, Perkin Elmer Co., Ltd., UK). A resolution of $4 \mathrm{~cm}^{-1}$ and 32 scans from 4000 to $400 \mathrm{~cm}^{-1}$ were used for each sample.

\section{Weathering procedure and instruments}

The powder dye sample of $0.250 \mathrm{~g}$ was loaded in a ceramic container. Each sample was kept out-door under the realistic atmosphere for 5, 10, 15 and 50 days. UV-Vis spectrophotometry (Thermo Scientific 4001/4, Thermo Electron Co., Ltd., MA, USA) was used to measure the absorbance of aqueous lac dye solution. The absorbance of aqueous dye solution with a fixed concentration of $0.15 \mathrm{~g} / \mathrm{L}(150 \mathrm{ppm})$ was scanned from 100$900 \mathrm{~nm}$. The optical images of the lac dye solutions were examined using digital camera (Canon, EOS-500D, Tokyo, Japan). The data of weathering investigation were gained from three measurements.

\section{Results and discussion}

\section{Nonisothermal decomposition}

Figure 2 shows the TG curves of lac dye after dynamic heating from room temperature to the selected temperatures as $60,90,150,250$ and $350{ }^{\circ} \mathrm{C}$ in air atmosphere. At temperature less than $150{ }^{\circ} \mathrm{C}$, the first mass-loss step occurs in the range of $40-150{ }^{\circ} \mathrm{C}$ and a mass loss of about $8 \%$ is observed (Fig. $2 \mathrm{a}-\mathrm{c}$ ). The first mass-loss stage mainly involves the evaporation of moisture in the materials. Generally, the hydrophilic substances tend to absorb and retain the moisture during the isolation and storing processes. From the polar structures of the main components in lac dye, it is the fact that the laccaic acids are hydrophilic and tend to retain the moistures in the intermolecular space. The moistures are mostly evaporated during heating from ambient temperature to $\sim 150{ }^{\circ} \mathrm{C}$, resulting in the mass loss as observed from the TG profiles. After dynamic heating to $150{ }^{\circ} \mathrm{C}$, the deflection of mass change (see arrows in Fig. $2 \mathrm{~d}-\mathrm{f}$ ) is clearly observed, indicating the

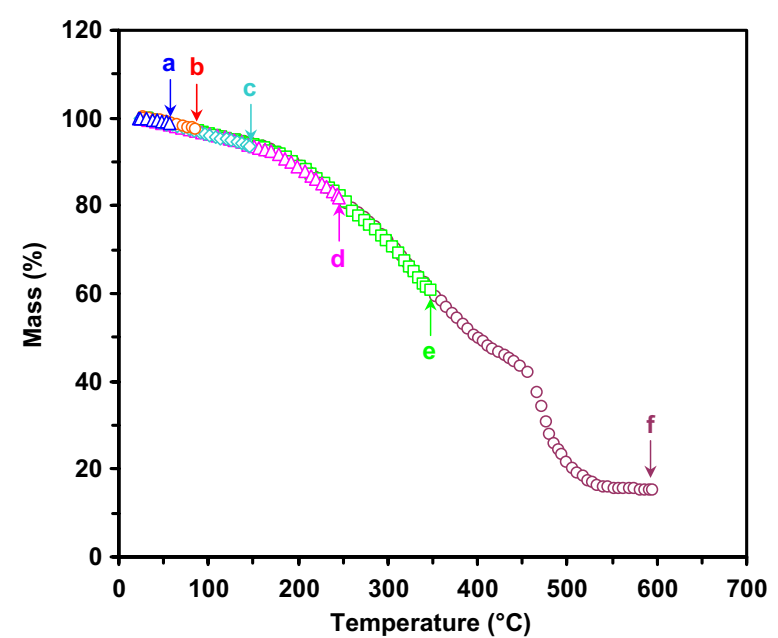

Fig. 2 TG profiles of lac dye under dynamic heating from room temperature to $a$ 60, b 90, c 150, d 250, e 350 and $f 600^{\circ} \mathrm{C}$ at heating rate of $10^{\circ} \mathrm{C} / \mathrm{min}$ in air 
change of mass-loss rate. Beyond this temperature, the degradation progressively occurs and next major change in mass loss rate is additionally observed around $440{ }^{\circ} \mathrm{C}$ (Fig. 2f). At temperature range of $150-440{ }^{\circ} \mathrm{C}$, the TG profile shows the mass loss of about $50 \%$. The rapid degradation with the mass loss of $25 \%$ is found at temperature higher than $440{ }^{\circ} \mathrm{C}$. Moreover, the char left content after degradation is found to be $\sim 17 \%$. In general, most organic materials thermally degraded and left small amount of char (less than $5 \%)$. However, due to the lac dye sample studied in this work mainly contains multicomponents of laccaic acids, the further reactions of the gas products may occur and/or these gas products may promote the char formation process during degradation. Hence, the relatively high amount of char is observed.

The mass loss rate and simultaneous DSC profiles corresponding to the TG curve (Fig. 2f) of lac dye dynamic heated to $600{ }^{\circ} \mathrm{C}$ are presented in Fig. 3a, b, respectively. It is seen that the constant rate concerning with the evaporation of moisture is observed under heating from room temperature to $150{ }^{\circ} \mathrm{C}$. At higher temperatures, the decomposition rate gradually increases to $\sim 1 \% / \mathrm{min}$ and a broad DTG curve containing
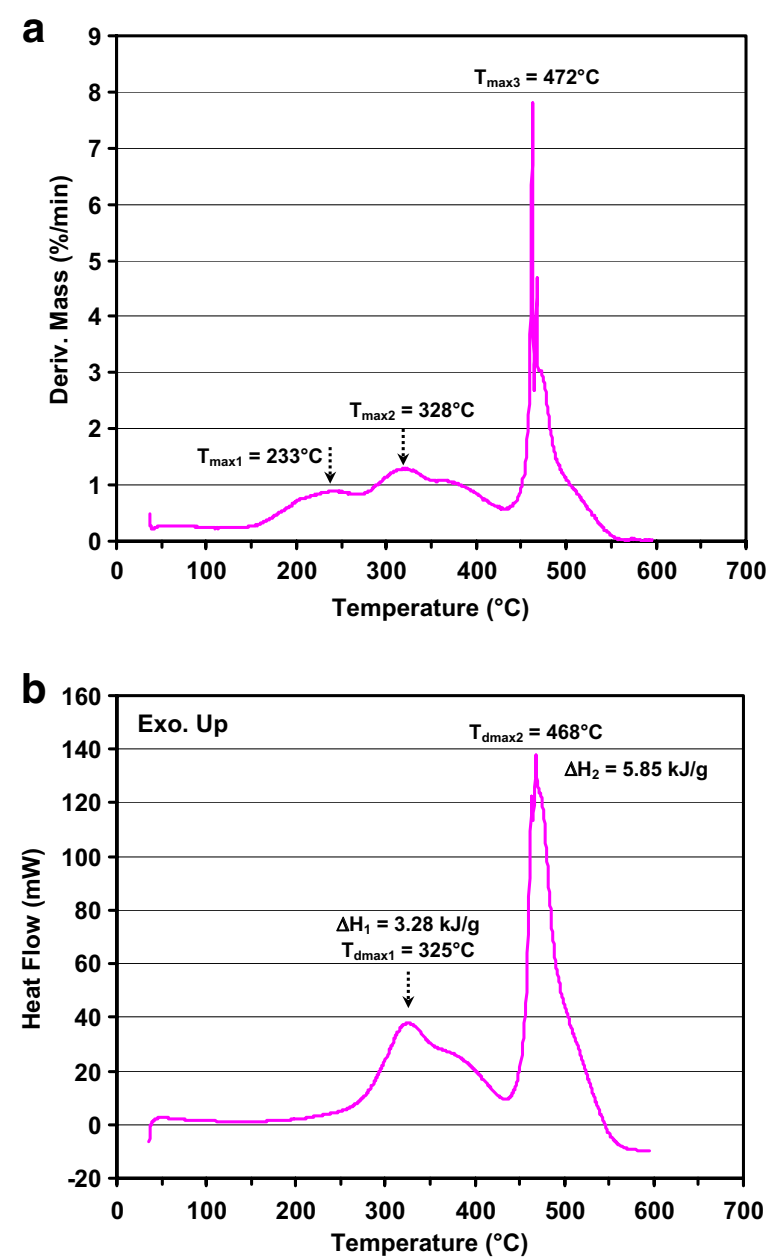

Fig. 3 DTG (a) and DSC (b) curves corresponding to the TG curve presented in Fig. 2f for lac dye under dynamic heating from room temperature to $600^{\circ} \mathrm{C}$ at heating rate of $10^{\circ} \mathrm{C} / \mathrm{min}$ in air 
multi-peaks with stretching up to $440{ }^{\circ} \mathrm{C}$ is observed. However, the rapid increase in mass-loss rate is observed beyond $\sim 450{ }^{\circ} \mathrm{C}$ and the degradation shows the maximum rate of $7.8 \% / \mathrm{min}$ at $472{ }^{\circ} \mathrm{C}$. In fact, the lac dye used in this study contains multi-components and therefore the complex thermo-oxidative decomposition can be expected. As stated that the first mass loss step mainly involves the evaporation of moisture, the next two major steps of mass loss would correspond the decomposition of lac dye. As seen from simultaneous DSC curve in Fig. 3, the thermo-oxidative decomposition of lac dye is exothermic process. This is normal for the degradation process in air which tends to involve the formation reaction. Moreover, two exothermic peaks of lac dye corresponding to the second and third major mass-loss steps are observed with possessing enthalpy changes of 3.28 and $5.85 \mathrm{~kJ} / \mathrm{g}$, respectively.

\section{FTIR characterization of lac dye}

FTIR is one of the spectroscopic methods widely used to characterize the functional groups and describe the interactions of molecules. Actually, the main coloring constituent of the lac dye is gained from the mixed laccaic acids. However, laccaic acid A, 3-[3-(2-acetamidoethyl)-6-hydroxyphenyl]-1,2,4,7-tetrahydroxyanthraquinone-5,6-dicarboxylic acid, is usually chosen as a representative for the lac dye to describe their kinetics and thermodynamics of adsorption. This is due to that the laccaic A is a major component of lac dye. Therefore, in this work, the lacaaic acid A is also mainly considered in correlation with the thermo-oxidative decomposition behavior. The FTIR spectra of lac dye before and after dynamic heating to the selected temperatures are shown in Figs. 4, 5. The broadening FTIR spectra of lac dye are observed, resulting from that the dye has various functional groups that can form H-bonds (Dokmaisrijan et al. 2013). Also, the broad FTIR spectra observed might be contributing to the different conformers of the dye (Svobodová et al. 2012). Before and after dynamic heating to 60, 90 and $150^{\circ} \mathrm{C}$ (Figs. 4a-c, 5a), slight change in FTIR spectra is observed. The FITR spectra of lac dye appeared are primarily assigned as $\mathrm{O}-\mathrm{H}$ rocking in hydroxyl and carboxylic groups (1100-1047 $\left.\mathrm{cm}^{-1}\right)$, deformation vibrations of $\mathrm{CH}_{2}$ and $\mathrm{CH}_{3}$ groups $\left(1500-350 \mathrm{~cm}^{-1}\right)$, $\mathrm{C}=\mathrm{O}$ stretching for $\mathrm{COO}^{-}$groups in conjugation with the $\mathrm{C}=\mathrm{C}$ bonds in aromatic ring (1720-1570 $\left.\mathrm{cm}^{-1}\right), \mathrm{C}-\mathrm{H}$ stretching $\left(3000-2850 \mathrm{~cm}^{-1}\right)$ and vibration band of $\mathrm{OH}$ groups (around $3300 \mathrm{~cm}^{-1}$ ). Under dynamic heating up to $250{ }^{\circ} \mathrm{C}$ (Fig. $5 \mathrm{~b}$ ), the significant change in FTIR spectra is clearly observed at the bands of $\sim 1671$ and $\sim 1047 \mathrm{~cm}^{-1}$ (see arrows) corresponding to the decomposition of two carboxylic groups and $\mathrm{C}-\mathrm{O}$ bonds, respectively. With heating to $350{ }^{\circ} \mathrm{C}$ (Fig. 5c), the stretching band of $\mathrm{C}-\mathrm{H}$ at $2927 \mathrm{~cm}^{-1}$ is diminished indicating the decomposition of $\mathrm{C}-\mathrm{H}$ bonds. Under heating to high temperatures $\left(250,350{ }^{\circ} \mathrm{C}\right)$, the sharp peak at $\sim 1107 \mathrm{~cm}^{-1}$, especially for the heated sample up to $350{ }^{\circ} \mathrm{C}$, is appeared. This may be due to the formation of small solid products consisting $=\mathrm{C}-\mathrm{H}$ bonds. However, due to the lac dye has many components with different chemical structures, the complex mechanisms would occur under thermo-oxidative condition.

\section{Thermo-oxidative stability of lac dye under dynamic heating}

As known that lac dye consists mainly of different types of laccaic acids, the complex degradation mechanism of lac dye is expected to take place. To obtain the reliable kinetic 

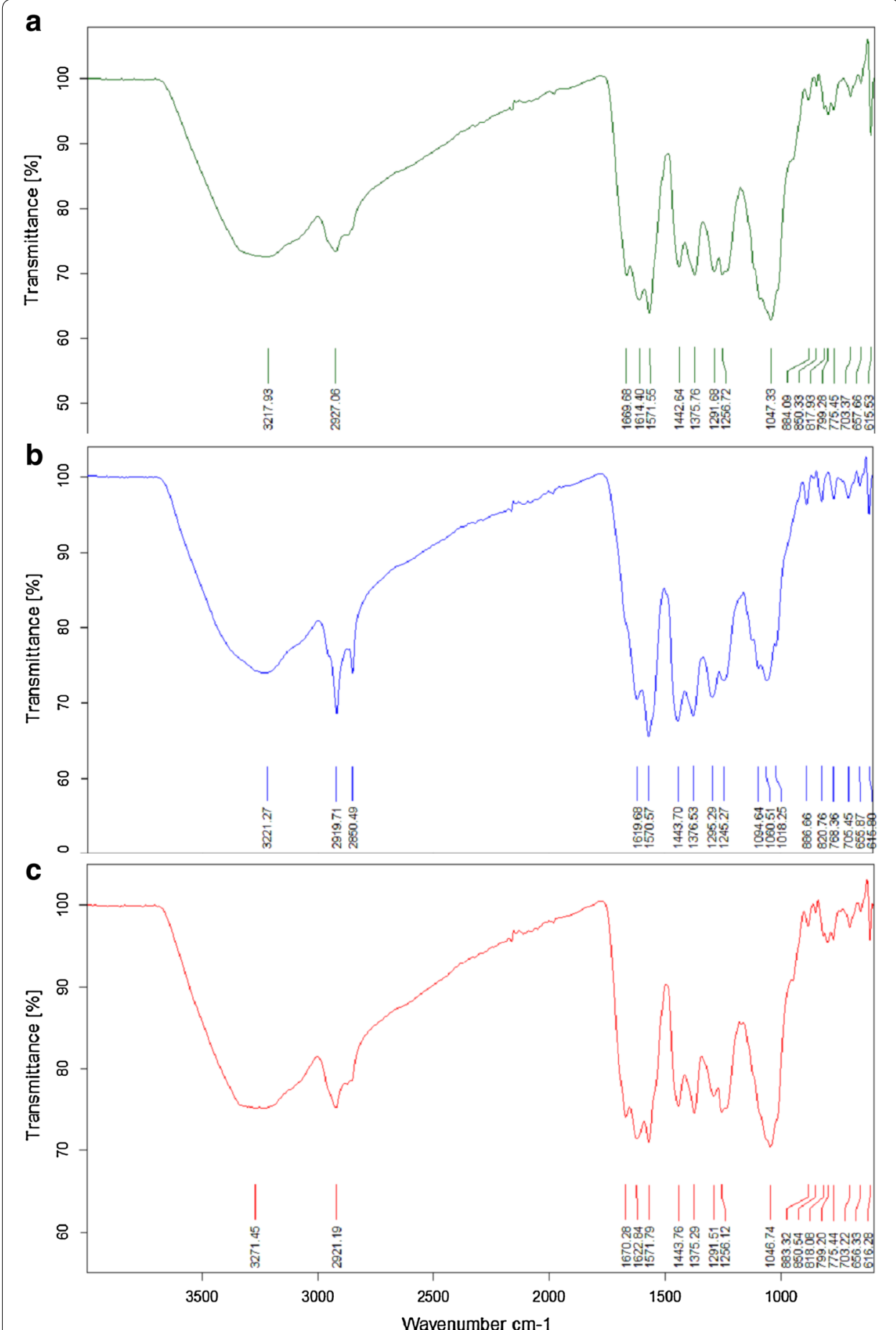

Fig. 4 FTIR spectra of lac dye before (a) and after dynamic heating from room temperature to $\mathbf{b} 60, \mathbf{c} 90^{\circ} \mathrm{C}$ at heating rate of $10^{\circ} \mathrm{C} / \mathrm{min}$ in air 

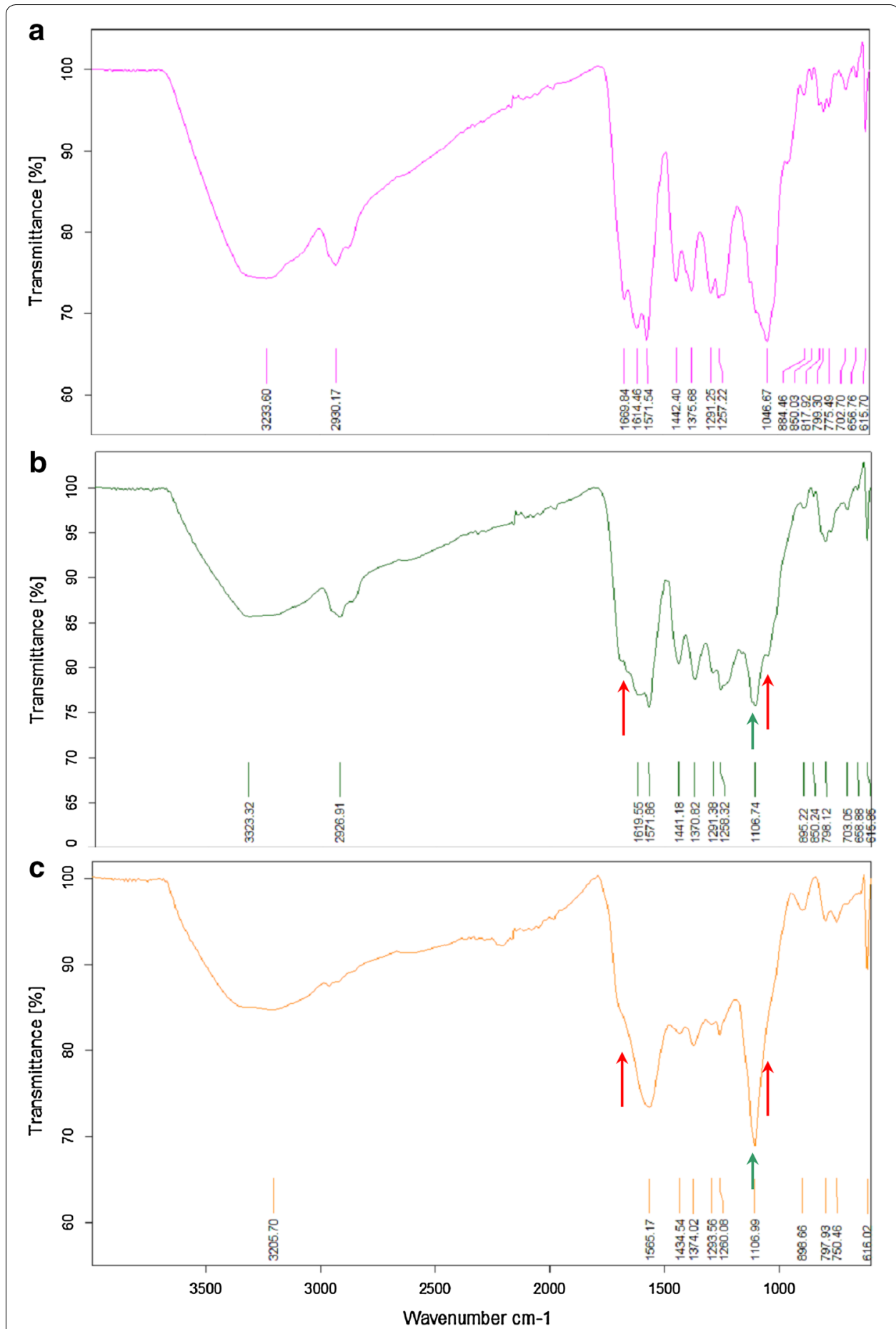

Fig. 5 FTIR spectra of lac dye after dynamic heating from room temperature to a $150, \mathbf{b} 250$ and $\mathbf{c} 350^{\circ} \mathrm{C}$ at heating rate of $10^{\circ} \mathrm{C} / \mathrm{min}$ in air

information for the solid state reactions of lac dye, the use of kinetic method without the knowledge of kinetic model is required. Flynn-Wall-Ozawa (F-W-O) isoconversional method (Ozawa 1965; Flynn and Wall 1966), is a relatively simple (model free) method of determining activation energy directly from mass versus temperature data, obtained 
at several heating rates. After providing the mass loss-temperature data at several heating rates, the activation energy can then be determined from the following equation:

$$
\ln \beta=\left[\frac{A E_{a}}{R g(\alpha)}\right]-5.3305-1.0516 \frac{E_{a}}{R T}
$$

where $g(\alpha)$ is an integral reaction type of kinetic function, $\beta$ is a heating rate in ${ }^{\circ} \mathrm{C} / \mathrm{min}$, $E_{\mathrm{a}}$ is an activation energy $(\mathrm{kJ} / \mathrm{mol})$ of the concurrent chemical reaction and physical process (apparent activation energy), $T$ is an absolute temperature (K), $R$ is the universal gas constant $(\mathrm{J} / \mathrm{K} \mathrm{mol})$, and $A$ is a frequency factor. A change in $E_{\mathrm{a}}$ with increasing degree of conversion is an indication of a complex reaction mechanism. Figure 6 shows the heating rates dependence of TG curves (Fig. 6a) and the F-W-O plots of $E_{\mathrm{a}}$ versus conversion extent $(\alpha)$ (Fig. 6b) for lac dye. In the present work, the F-W-O calculation was selected in the temperature range of $150-300{ }^{\circ} \mathrm{C}$ corresponding to the major degradation step of lac dye and the TG curves appear without overlapping. The $E_{\mathrm{a}}$ values at various percent conversion extents are presented in Table 1 . It is seen that the $E_{\mathrm{a}}$ value progressively
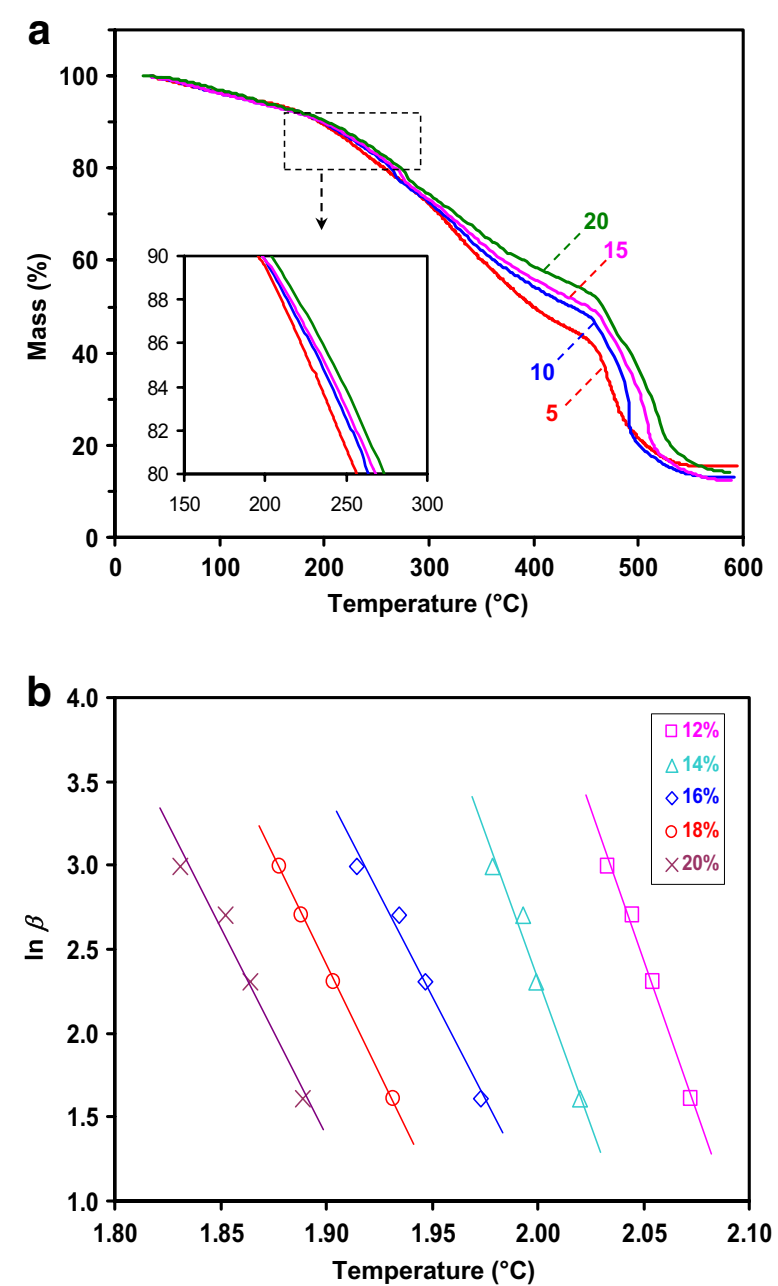

Fig. 6 TG curves (a) at heating rates of 5, 10, 15 and $20^{\circ} \mathrm{C} / \mathrm{min}$ in air and Flyn-Wall-Ozawa plots $(\mathbf{b})$ for the degradation at temperature range of $150-300^{\circ} \mathrm{C}$ 
Table 1 Thermo-oxidative activation energies $\left(E_{\mathrm{a}}\right)$ at various mass losses of lac dye

\begin{tabular}{lll}
\hline \% Mass loss & $\boldsymbol{E}_{\mathrm{a}}(\mathbf{k J} / \mathbf{m o l})$ & $\boldsymbol{r}^{2 *}$ \\
\hline 12 & 283 & 0.9900 \\
14 & 275 & 0.9710 \\
16 & 193 & 0.9780 \\
18 & 205 & 0.9990 \\
20 & 195 & 0.9680 \\
\hline${ }^{*} r^{2}$ Means correlation coefficient for linear fit analysis & &
\end{tabular}

decreases as the conversion extent increases. However, the average $E_{\mathrm{a}}$ value of $230 \mathrm{~kJ} /$ mol suggests a high thermo-oxidative stability of lac dye under nonisothermal heating.

Thermo-oxidative stability of lac dye under isothermal heating

To gain a complete information of the degradation kinetics, isothermal TG analyses are also investigated. The isothermal decomposition behavior is shown in Fig. 7. The isothermal TG and DTG curves are shown in Fig. 7a, b, respectively. The TG and DTG profiles of lac dye are nearly the same under isothermal heating at 110,130 and $150{ }^{\circ} \mathrm{C}$ for 0-10 min. This indicates that the mass loss mainly involve the evaporation of moisture during heating at 110,130 and $150{ }^{\circ} \mathrm{C}$ for the first $10 \mathrm{~min}$. After heating for longer time, it is seen that mass loss progressively increases with temperature. Under isothermal heating at $170{ }^{\circ} \mathrm{C}$, lac dye obviously exhibits a rapid degradation during the first $25 \mathrm{~min}$ of isothermal heating. However, the mass loss content during the first $10 \mathrm{~min}$ of heating at $170{ }^{\circ} \mathrm{C}$ is clearly lower than those at 110,130 and $150{ }^{\circ} \mathrm{C}$. Note that, the time at maximum rate of decomposition $\left(t_{\max }\right)$ of the sample is increased with increasing isothermal temperature. In the case of simultaneous DSC curves (Fig. 7c), it is seen that the single endothermic peak is observed during heating time of $10-20 \mathrm{~min}$. With increasing heating temperature, the exothermic peaks reveal at the higher heating time. Moreover, the enthalpy is mostly found to increase with higher heating temperature.

For solid state degradation reaction, the rate of decomposition $(d \alpha / d t)$ can be described by (Tanaka 1995; Nam and Seferis 1991; Vyazovkin and Wight 1997).

$$
\frac{d \alpha}{d t}=k(T) f(\alpha)
$$

where $k(T)$ and $\mathrm{f}(\alpha)$ are the reaction rate constant and a conversion function, respectively. By replacing $k(T)$ using Arrhenius equation, $k(T)=A e^{-E_{a} / R T}$, the rate of decomposition becomes.

$$
\frac{d \alpha}{d t}=f(\alpha) A e^{-E_{a} / R T}
$$

By integration of Eq. (3), $g(\alpha)$, is obtained:

$$
g(\alpha)=A e^{-E_{a} / R T} t
$$


where $t$ is a degradation time. By writing the Eq. (4) in the form of natural logarithmic expression, the following equation is obtained:

$$
\ln t=\ln g(\alpha)-\ln A+\frac{E_{a}}{R T}
$$

Equation (5) is known as a standard isoconversional method (Vyazovkin 2000). The $\ln t$ corresponding to a certain mass loss is linearly dependent on $1 / T$. The $E_{\mathrm{a}}$ can be evaluated from the slope of the linear relationship of $\ln t$ versus $1 / T$. For instance, the plot of $\ln t$ against $1 / \mathrm{T}$ corresponding to the mass losses of $3 \%$ of lac dye is presented in Fig. $7 \mathrm{~d}$. The $E_{\mathrm{a}}$ value calculated from the slope of the straight line is $57.9 \mathrm{~kJ} / \mathrm{mol}$. It is seen that the isothermal activation energy of lac dye appears to be lower than those of the nonisothermal one, indicating a lower thermo-oxidative stability of lac dye under exposing to the isothermal heating.

\section{Effect of dynamic heating on absorbability of lac dye solution}

To investigate the influence of dynamic heating on the absorbability of lac dye, the measurement of absorbance using UV-Vis spectroscopic method for the dye solution was employed. After dynamic heating the lac dye to the selected temperatures, the absorbance of lac dye solutions in correlation with their colors is shown in Fig. 8. It is roughly seen that no significant change in fading of the dye solutions for the dye solution before and after dynamically heated at $60-150{ }^{\circ} \mathrm{C}$. The remarkable fading of lac dye solution is clearly observed for the dye heated to $250{ }^{\circ} \mathrm{C}$ (Fig. 8a). Under dynamic heating to
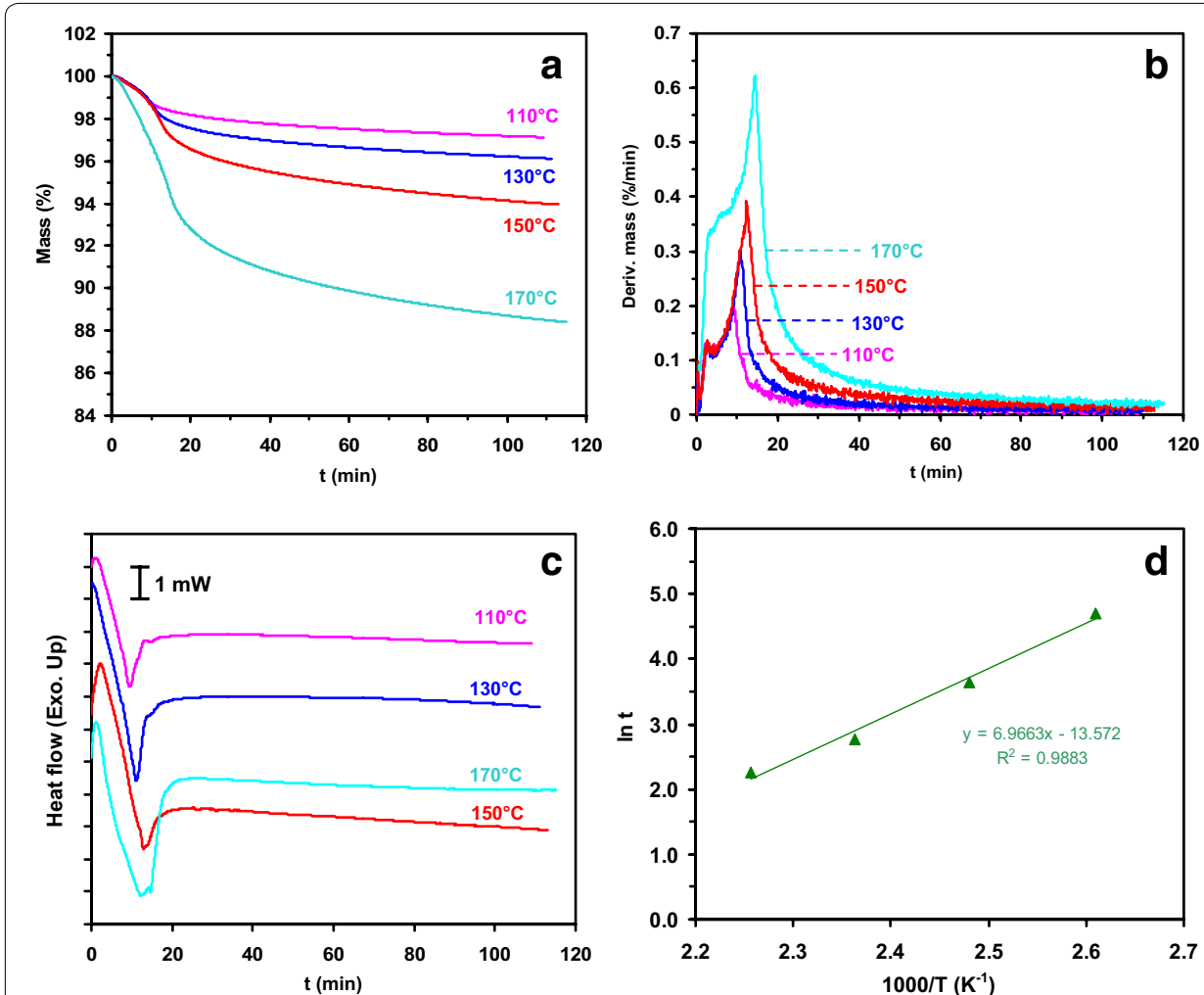

Fig. 7 Isothermal TG (a), DTG (b), simultaneous DSC curves (c) and the standard isoconversional plot for the degradation of lac dye (d) 


\section{a}
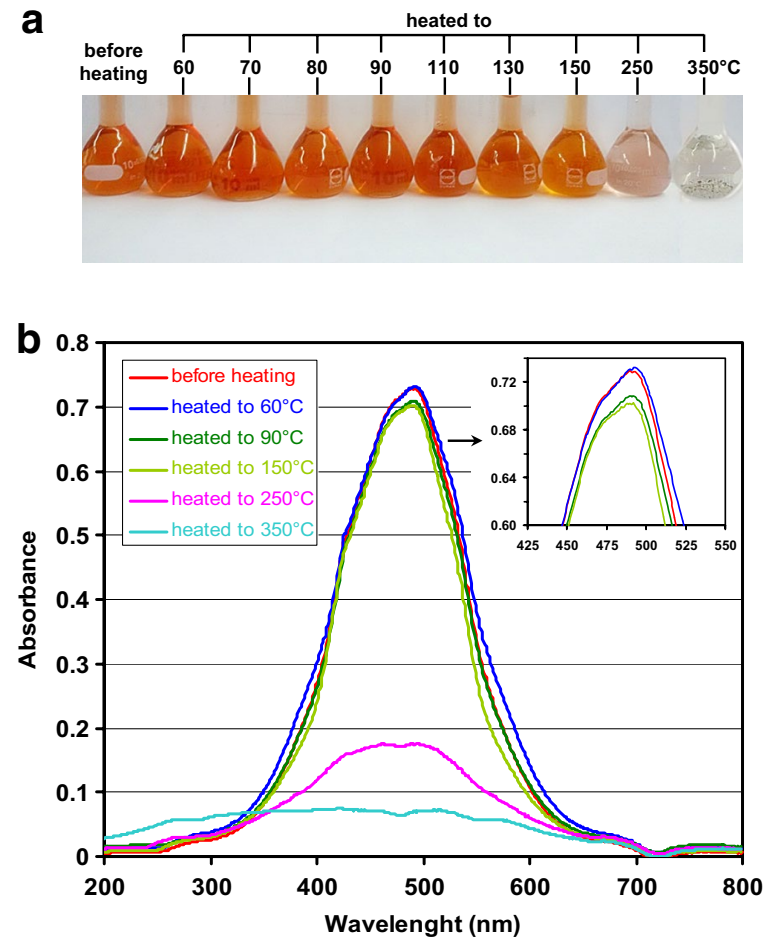

Fig. 8 Images (a) and absorbance (b) of dye solutions prepared from lac dye before and after dynamic heating to the selected temperatures at heating rate of $10^{\circ} \mathrm{C} / \mathrm{min}$ in air

$350{ }^{\circ} \mathrm{C}$ or higher, the solution is colorless and some suspended residues or ashes were observed. The obtained results suggest that the lac dye clearly degrade under dynamic heating at the temperature $>150^{\circ} \mathrm{C}$. The absorbance of the lac dye solution is presented in Fig. 8b. The major high absorption band at $\sim 490 \mathrm{~nm}$ in the visible region is observed corresponding to the singlet $\pi \rightarrow \pi^{*}$ transition with $83 \%$ MO contributions (Dokmaisrijan et al. 2013). Meanwhile, the HOMO and LUMO levels mainly differ at the delocalization at ${ }^{* *} \mathrm{COOH}$ group. The transition involves an electron density transfers from anthraquinone ring to the carboxylic group ("COOH) (see Fig. 1a). As seen from Fig. 8b, the maximum absorbance intensity (at $\lambda_{\max } \sim 490 \mathrm{~nm}$ ) for the solutions containing lac dye before and after heating to $60-150{ }^{\circ} \mathrm{C}$ lies in the range of $0.70-0.75$. Although the spectra for the solutions with the dye heated to 70 and $80{ }^{\circ} \mathrm{C}$ are not shown here, the shape and maximum intensity of both samples are respectively the same and comparable, compared to those of the solutions containing $90{ }^{\circ} \mathrm{C}$-heated dye. Interestingly, for the solution of the dye samples heated to 250 and $350{ }^{\circ} \mathrm{C}$, the remarkable drop in absorbance intensity is clearly observed. This arises from that the stability of the dye is not prolonged at very high temperatures. As compared from the FTIR spectra of lac dye before 
and after heating to 250 and $350{ }^{\circ} \mathrm{C}$ (Figs. 4, 5), the vibration bands of $\mathrm{COOH}$ groups conjugated with the $\mathrm{C}=\mathrm{C}$ bonds of the anthraquinone ring $\left(1720-1570 \mathrm{~cm}^{-1}\right)$ clearly change. The degradation of $\mathrm{COOH}$ groups directly affects the conjugated systems and lowers the ability of electron transfers from anthraquinone ring to $\mathrm{COOH}$ groups. The absorbance profiles of lac dye solutions obtained from the present study relate well with their fading properties as shown in Fig. 8a.

\section{Effect of atmospheric weathering on absorbability of lac dye solutions}

Normally, the natural dyes must encounter the degradation phenomena at almost every stage in storing, preparing, processing and application stages. Therefore, the understanding of stability of lac dye in relation with its coloring performance under realistic atmosphere is very important in suggesting their suitability of applications. Figure 9 shows the effect of out-door weathering under local atmosphere on FTIR spectra of lac dye. Under weathering for 10 and 15 days, no significant change in the FTIR spectra compared with the controlled sample is observed. Interestingly, the band at $\sim 1063 \mathrm{~cm}^{-1}$ is clearly shifted to $\sim 1016 \mathrm{~cm}^{-1}$ under weathering for 50 days. The results indicate that the weathering condition strongly affect the $\mathrm{O}-\mathrm{H}$ bonds of hydroxyl and/or in carboxylic groups. This means that the initial reaction would mainly occur at these functional groups. However, although the reaction has been occurred at $\mathrm{OH}$ sites, the conjugated systems, especially for electron transfer from anthraquinone ring to $\mathrm{COOH}$ groups, are partly still existed. This is evident from the spectroscopic results as seen from Fig. 10. It is seen that the absorbance intensity progressively decreases (Fig. 10a) with weathering time which relate with color fading of dye solutions (Fig. 10b). The obvious change in absorbance profile is observed with weathering for 50 days. That is, small and sharp absorption peak is observed and the maximum absorbance intensity is much lower than those of other samples. This indicates that, under exposing to long weathering time, the reaction of lac dye mainly occurs at $\mathrm{O}-\mathrm{H}$ bonds of carboxylic groups, resulting in the change of absorbability of red chromophores.

\section{Conclusion}

In this work, effects of thermo-oxidative heating and atmospheric weathering on stability of lac dye were investigated. Under dynamic heating, the lac dye started to degrade at temperatures higher than $150^{\circ} \mathrm{C}$ which mainly involved the thermo-oxidative reaction at carboxylic groups in conjugation with the $\mathrm{C}=\mathrm{C}$ bonds of the anthraquinone ring. Before and after dynamic heating to $60-150^{\circ} \mathrm{C}$, the absorbance profiles of each lac dye solution were not significantly different. Under heating the lac dye to higher temperatures, the absorbance significantly dropped resulting from the degradation of the chromophores. Under long weathering period, the chemical change mainly involved $\mathrm{O}-\mathrm{H}$ bonds of 

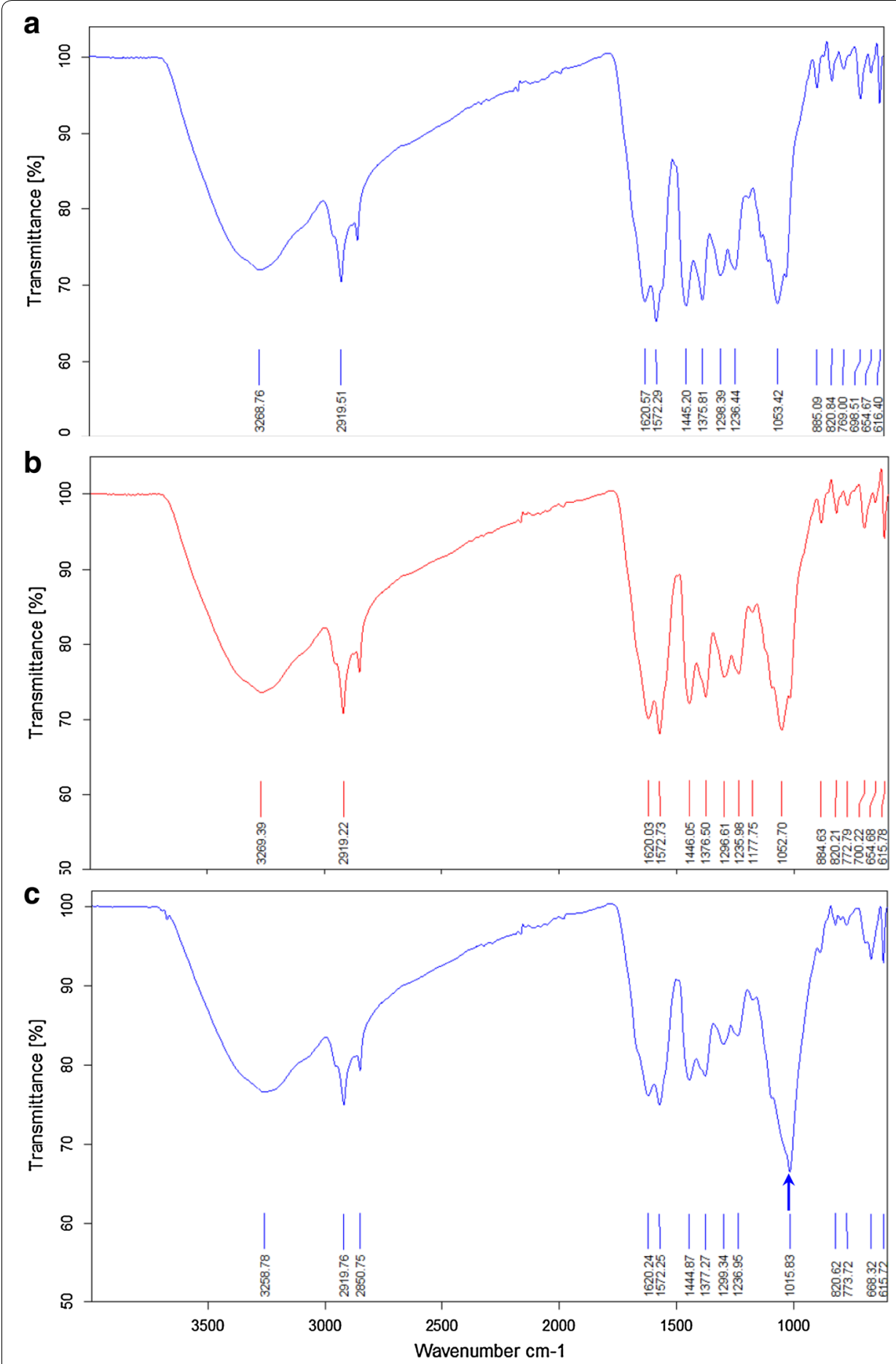

Fig. 9 FTIR spectra of lac dye after atmospheric weathering for a $10, \mathbf{b} 15$ and $\mathbf{c} 50$ days

hydroxyl and carboxylic groups. This change also strongly lowered the absorbability of lac dye solution. The obtained results provided helpful information about thermo-oxidative and weathering stability of lac dye which is useful for maintenance, preparation, dyeing process and realistic applications. 


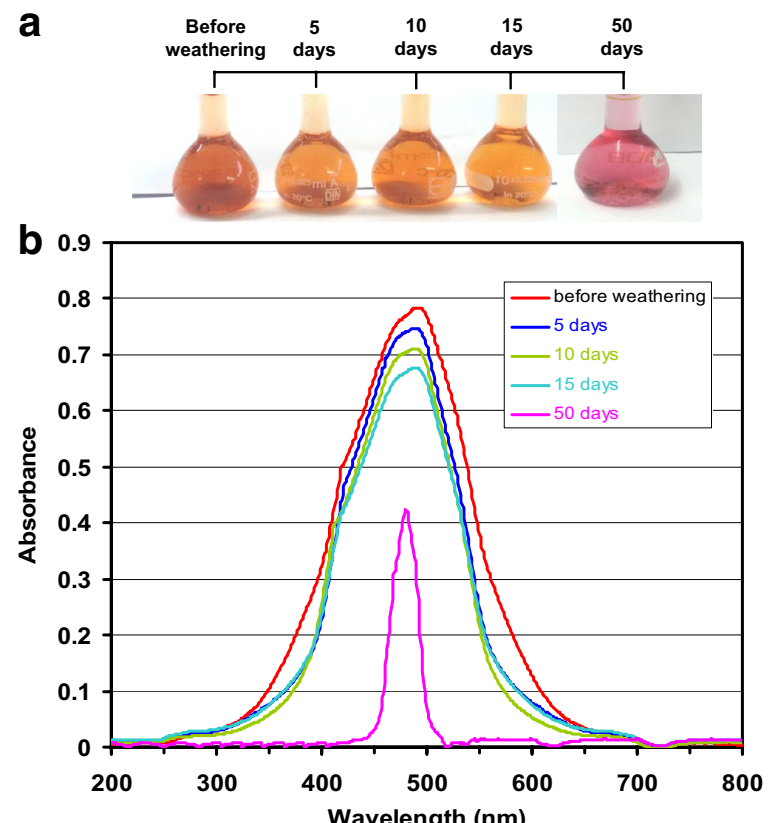

Fig. 10 Images (a) and absorbance (b) of dye solutions prepared from lac dye before and after atmospheric weathering for various times

Authors' contributions

Both authors read and approved the final manuscript.

\section{Acknowledgements}

The authors would like to acknowledge Center of Excellence for Innovation in Chemistry (PERCH-CIC) and Mahasarakham University (Fast-track Grant 2015) for their partial financial supports.

\section{Competing interests}

The authors declare that they have no competing interests.

Received: 25 March 2016 Accepted: 2 August 2016

Published online: 28 September 2016

\section{References}

Ahn, C. (2011). Analysis of amur cork tree extract and dyed silk upon thermal degradation treatment. Journal of the Korean Society of Clothing and Textiles, 35(10), 1228-1241.

Ahn, C., \& Obendorf, S. K. (2004). Dyes on archaeological textiles: Analyzing alizarin and its degradation products. Textile Research Journal, 74(11), 949-954.

Ahn, C., Zeng, X., Li, L., \& Obendorf, S. K. (2014). Thermal degradation of natural dyes and their analysis using HPLC-DADMS. Fashion and Textiles, $1,22$.

Boonla, K., \& Saikrasun, S. (2013). Influence of silk surface modification via plasma treatments on adsorption kinetics of lac dyeing on silk. Textile Research Journal, 83, 288-297.

Chairat, M., Rattanaphani, S., Bremner, J. B., \& Rattanaphani, V. (2005). An adsorption and kinetic study of lac dyeing on silk. Dyes and Pigments, 64, 231-241.

Cristea, D., \& Vilarem, G. (2006). Improving light fastness of natural dyes on cotton yarn. Dyes and Pigments, 70, 238-245.

Dokmaisrijan, S., Payaka, A., Tantishaiyakul, V., Chairat, M., Nimmanpipug, P., \& Lee, V. S. (2013). Conformations and spectroscopic properties of laccaic acid A in the gas phase and in implicit water. Spectrochimica Acta Part A: Molecular and Biomolecular Spectroscopy, 105, 125-134.

Downham, A., \& Collins, P. (2000). Colouring our foods in the last and next millennium. International Journal of Food Science \& Technology, 35, 5-22.

Egerton, G. S., \& Morgan, A. G. (1970). The photochemistry of dyes. II. Some aspects of the fading Process. Journal of the Society of Dyers and Colourists, 86, 242-249.

Flynn, J. H., \& Wall, L. A. (1966). General treatment of the thermogravimetry of polymers. Journal of research of the National Bureau of Standards, 70A, 487-523.

Gantz, G. M., \& Sumner, W. G. (1957). Stable ultraviolet light absorbers. Textile Research Journal, 27, 244-251. 
Janhom, S., Griffiths, P., Watanesk, R., \& Watanesk, S. (2004). Enhancement of lac dye adsorption on cotton fibres by poly(ethyleneimine). Dyes and Pigments, 2004(63), 231-237.

Kamel, M. M., El-Shishtawy, R. M., Youssel, B. M., \& Mashaly, H. (2007). Ultrasonic assisted dyeing. IV. Dyeing of cationised cotton with lac natural dye. Dyes and Pigments, 73, 279-284.

Kongkachuichay, P., Shitangkoon, A., \& Chinwongamorn, N. (2002). Thermodynamics of adsorption of laccaic acid on silk. Dyes and Pigments, 53, 179-185.

McLaren, K. (1956). The spectral regions of daylight which cause fading. Journal of the Society of Dyers and Colourists, 72, 86-99.

Moeyes, M. (1993). Natural dyeing in Thailand. Bangkok: White Lotus.

Nam, J. D., \& Seferis, J. C. (1991). A composite methodology for multistage degradation of polymers. Journal of Polymer Science Part B: Polymer Physics, 29, 601-608.

Nayar, T. S., Binu, S., \& Pushpagandhan, P. (1994). Uses of plants and products in traditional Indian mural paintings. Economic Botany, 53, 41-50.

Oka, H., Ito, Y., Yamada, S., Kagami, T., Hayakawa, J., Harada, K. I., et al. (1998). Separation of lac dye components by highspeed counter-current chromatography. Journal of Chromatography A, 813, 71-77.

Ozawa, T. (1965). A new method of analyzing thermogravimetric data. Bulletin of the Chemical Society of Japan, 38, 1881.

Padfield, P., \& Landi, S. (1996). The light-fastness of the natural dyes. Studies in Conservation, I/(4), 181-196.

Ramos, P., Gieseg, S. P., Schuster, B., \& Esterbauer, H. (1995). Effect of temperature and phase transition on oxidation resistance of low density lipoprotein. Journal of Lipid Research, 36(10), 2113-2128.

Saengsuwan, S., \& Saikrasun, S. (2012). Thermal stability of styrene-(ethylene butylene)-styrene-based elastomer composites modified by liquid crystalline polymer, clay, and carbon nanotube. Journal of Thermal Analysis and Calorimetry, 110, 1395-1406.

Sribenja, S., \& Saikrasun, S. (2015). Adsorption behavior and kinetics of lac dyeing on poly(ethyleneimine)-treated bamboo fibers. Fibers and Polymers, 16(11), 2391-2400.

Svobodová, E., Bosáková, Z., Ohlídalová, M., Novotná, M., \& Němec, I. (2012). The use of infrared and Raman microspectroscopy for identification of selected red organic dyes in model colour layers of works of art. Vibrational Spectroscopy, 63, 380-389.

Tanaka, H. (1995). Thermal analysis and kinetics of solid state reactions. Thermochimica Acta, 267, 29-44.

Vyazovkin, S. (2000). Computational aspects of kinetic analysis: Part C. The ICTAC Kinetics Project—-the light at the end of the tunnel? Thermochimica Acta, 355, 155-163.

Vyazovkin, S., \& Wight, C. A. (1997). Isothermal and nonisothermal reaction kinetics in solids: In search of ways toward consensus. The Journal of Physical Chemistry A, 101(44), 8279-8284.

\section{Submit your manuscript to a SpringerOpen ${ }^{\circ}$ journal and benefit from:}

- Convenient online submission

\section{Rigorous peer review}

- Immediate publication on acceptance

- Open access: articles freely available online

- High visibility within the field

- Retaining the copyright to your article

Submit your next manuscript at $\boldsymbol{\nabla}$ springeropen.com 